This is a post-print version of the following article:

Räsänen Jenni-Mari, Saario Sirpa. (2015) Telecare as Institutional Interaction: Checking up on the Client and Creating Continuity. Journal of Technology in Human Services 33 (3), 205-224.

\begin{abstract}
This article studies the functions of telecare-mediated discussions in mental health floating support services. Home Screen, the telecare studied, is a touchscreen computer software that enables real-time audiovisual contact between users. The results indicate that Home Screen functions as a medium to discuss and check clients' current situation and to sum up and plan their goals. The functions of Home Screen are not stable, but instead they are produced and negotiated in the interaction. Portraying Home Screen as a transitional device, this article supports the view that telecare enables clients to remain in their homes while receiving the care needed.
\end{abstract}

Keywords: information and communication technology, institutional interaction, floating support services, telecare, telehealth

"This is an Accepted Manuscript of an article published by Taylor \& Francis Group in Journal of Technology in Human Services 12/08/2015, available online: http:// 


\section{Telecare as Institutional Interaction: Checking up on the Client and Creating Continuity}

\section{Introduction}

Recently, there have been a lot of developments in the delivery of human services via information and communications technologies (ICTs). One example of these developments is telecare which signifies the use of ICTs to provide support for vulnerable people living in the community (Barlow, Bayer \& Curry, 2005). In other words, by remotely monitoring clients' needs for support, telecare aims to enable clients with different care needs to remain in their own homes (Eccles, 2010; Sorell \& Draper, 2012). The concept of telecare can be situated in the wider frame of telehealth, which is commonly used to describe the exchange of health information and the provision of services through ICTs when participants are physically separated (Hebert, 2001).

At the policy level, the introduction of telecare has become a key feature in the development of advanced industrial societies. In the UK, there is even a move towards no less than a mainstream delivery of telecare (Barlow et al., 2005; Scottish Government, 2008, 6, p. 18-19). Telecare is gaining more importance also in the context of this study, i.e. Finland where current governmental policies on mental health encourage services that are provided in service users' homes (Plan for mental health and substance abuse work, 2010). As Report on the development of mental health service users' housing (2012) states, the potential of technology and related tools should be thoroughly investigated. These home-based technologies are seen to increase the wellbeing of clients, for example by monitoring the taking of medication or supporting participation in social life (p. 36). 
The setting of this article is Finnish mental health floating support services. Floating support is provided by support workers who go to clients' homes and usually takes the form of home visits. Studying telecare in the context of floating support services is apt, because both telecare and floating support are strongly based on the idea of transferring clients from institutional environments to home-based settings (Sorell \& Draper, 2012). By enabling clients to live independently in their homes, floating support services are an essential community resource that replaces institutional care (Crutchfield \& Burnie, 2001; Sharples, Gibson \& Calvin, 2002).

There is ample literature on telecare imported into human services. First, positive findings are reported on the benefits of telecare regarding its financial impact on services: it is cost-effective and thus save resources, both timewise and economically (Barlow et al., 2005; Beale, Truman, Sanderson \& Kruger, 2010; Mielonen, Ohinmaa, Moring \& Isohanni, 2002). Second, telecare is found to be useful in overcoming barriers created by long distances and reaching people in remote areas (Kennedy \& Yellowlees, 2000; Schopp, Demiris \& Glueckauf, 2006). Third, telecare is found to improve access to care and to promote independence as clients can remain at home while still receiving support (Beale et al., 2010; Wootton et al., 2012). However, telecare remains less studied in the actual interaction between the users (for example Aceros, Cavalcante, Domenech, 2013; Wakefield, Hulman, Ray, Morse \& Kienzle, 2004). Also, telecare studies tend to concentrate on specific user groups such as the elderly (e.g. Barlow et al., 2005; Eccles, 2010; Frennert, Forsberg \& Östlund, 2013) and people with longterm somatic illness (e.g. Kubota et al., 2013; Zissman, Lejbkowicz \& Miller, 2012) - thus leaving mental health clients and telecare-mediated situations less studied.

In this article, we approach telecare from the point of view of institutional interaction. This signifies focussing on the interaction between the client and the worker via telecare in authentic situations of a particular institutional context. The telecare device under study can be 
defined as enabling "synchronous webcamera-based interventions in which a professional is in live communication with a client" (Perle \& Nierenberg, 2013, p. 23). By studying telecare as a tool that sets a frame for communication between the client and the worker (see also Pilnick, Hindmarsh \& Teas Gill, 2009), we aim to demonstrate how telecare functions in situ and how the telecare-mediated discussions situate in the larger institutional context of floating support, especially in terms of more traditional home visits (Juhila, Hall \& Raitakari, forthcoming). This type of research that is situated in the "real world" settings of telecare is recommended by Perle and Nierenberg (2013), as it will aid the determination of those interventions that can be adequately translated from a face-to-face medium to a telecare format.

\section{Home Screen - Telecare Device Used in Floating Support Services}

The setting of this study is a Floating Support Service in a large Finnish city. Floating support contains services that are provided in users' own homes, i.e. most often by home visits by qualified mental health or social care workers. In their visits, workers help with and advise on financial matters, medicine taking, cleaning, creating and maintaining social relations, and in clients' everyday problems. Floating Support Services are managed by a large mental health organisation, under contract with the local municipality, with an average caseload of 60 clients. The workers conduct home visits and are available daily in the office from Monday to Saturday. During these times certain clients make contact via Home Screen. Home Screen is a touch screen computer with video conferencing software programme that enables real-time audio visual contact between users in different settings. The connection provided by Home Screen is protected and thus appropriate for confidential client-professional discussions. Besides beforehand agreed one-to-one discussions, Home Screen can be used for accessing the internet and group discussions. Hence, it also serves as an arena for peer support between clients. Home Screen can also be used spontaneously for emergency calls in situations that require immediate 
support from the professionals. In Floating Support Service, Home Screen is used as one part of home visiting alongside other forms of contact between workers and clients. The device was piloted in the EU project T -Seniority (2008-2010) in which Finland was a participant. Thus Home Screen was first used with elderly people in the city and later adopted by the mental health Floating Support Service of the same city. In the Finnish context the city in question is quite populous compared to e.g. remote areas of Northern Finland with long geographic distances.

In this article, the Home Screen discussions are understood as institutional dialogues per se that are framed by specific institutional goals and tasks that are tied to institutional roles of e.g. professional and client (Juhila, Mäkitalo \& Noordegraaf, 2014, p. 20-22; Drew \& Heritage, 1992, p. 21-24; Heritage, 1997, p. 106; Drew \& Sorjonen, 1997, p. 74). Hence, the Home Screen discussions are not just regular, everyday talk but "talk with a mission" (Juhila et al., 2014, p. 9). The brochure of the Floating Support Services state that the main institutional goal is to aid people with long-term mental illness to manage living in their own home. This goal is largely accomplished by regular client-professional encounters, usually in the form of home visits. Other goals reported are the use of a psychoeducational approach which signifies effective information sharing with the client and his family and the construction of a holistic view on the client's situation (brochure of Floating Support Service). The brochure defines the tasks of composing an initial assessment and rehabilitation plan, networking and training clients to improve their everyday living skills. In addition to these, there are specific goals related to the IT-based services (implying to Home Screen) regarding more flexible access to help and the strengthening of the sense of community. 


\section{Data}

The data ${ }^{1}$ consists of six video-recorded Home Screen discussions between clients and workers. A total of four different workers and four different clients appeared in the videos. The analysed Home Screen discussions were agreed on beforehand between workers and clients and hence did not include emergency calls or group discussions. The discussions between an office-based worker and a home-based client were mediated by Home-Screen in which they could see their own face, as well as the face of the other party, on the screen. The researcher set the videorecording on in the floating support office and then left the room. While the worker and the client communicated via Home Screen's webcam, the camera recorded the communication for data collection purposes, which lead to a double-video recording. Wilińska and Bülow (2014) note that video recording for research purposes may affect the relationships existing between the parties (see also Eräsaari, 1999; Räsänen, 2014). Partly due to the presence of the two video cameras, we presume that the participants' ordinary communication was not hugely influenced by the research video camera, as they were already exposed to Home Screen's webcam.

Before data collection, the researcher called the clients and asked for their permission to record the telecare discussion. The research project was also generally presented and discussed with the clients and the professionals. Participation in the recorded video sessions was voluntary, and those who agreed to participate also signed consent forms. Information sheets on the research were available during the fieldwork. The research ethics committee of the university where the research is based gave a statement of approval in 2011. In the spring 2014 the authors arranged a follow up meeting with the organization involved in the study. During the meeting the workers reported no significant changes relating to the use of Home Screen or its technical properties. 


\section{Methods \& Analysis}

In this paper our primary aim is to explore the functions of Home Screen produced in actual, naturally occurring situations. Thus, our analysis is based on the ethnomethodological idea of technologies in action (Button, 1993; Heath \& Luff, 2000). Within this framework, our focus is on the observable, explicit functions of Home Screen and how they are accomplished in the interaction (Frers, 2009, pp. 286, 296). When doing this kind of analysis, it enables us to see the "seen, but unnoticed" (Heath \& Hindmarsh, 2002, p. 102-103) functions of Home Screen. It also increases our knowledge of "what is at stake" in these particular institutional discussions (Juhila et al., 2014, p. 9). Video-recorded data enables us to see both the client's face and the worker's face, gestures, expressions, and some parts of the surroundings where discussions take place (see also Heath \& Luff, 2000, p. 30). These effects of non-verbal communication are also included in the analysis.

As we approach Home Screen from the point of view of institutional interaction, we pay special attention to it as a tool that sets a frame for communication between the client and the worker in the context of floating support services. Within this framework, we will also observe the different ways both workers and clients orient to Home Screen with their respective roles and responsibilities (Drew \& Sorjonen, 1997, p. 74; Juhila et al., 2014, p. 20-22). We observe whether there are certain topics and agendas that the participants want to achieve in an institutional sense and whether there are any asymmetries between the participants e.g. in their knowledge about the situation at hand or between their participation in-situ (Juhila et al., 2014, p. 20-22 building on Drew \& Heritage, 1992, p. 21-24; Heritage, 1997, p. 106). One way of achieving our goals is to consider how the general institutional goals reported in the brochure of Floating Support Services are reflected in Home Screen discussions. Also, the alignment between the participants is considered to discover whether they orient differently towards institutional tasks and agendas (Zimmermann, 1998; Juhila \& Abrams, 2011). 
Overall, the analysis is based on the ethnomethodological idea of members' methods; how the functions and institutional features of Home Screen are actually oriented to, manifested and shaped in the particular actions of workers and clients (Drew \& Heritage, 1992, p. 24; Juhila et al., 2014, p. 12-13; Garfinkel, 1967). Based on these methodological premises, we present the following research question: How does Home Screen function as a part of the institutional floating support services?

\section{Results}

In the first phase of analysis, we went through the data several times. Our initial finding is that each of the six Home Screen discussions can be fitted in a short time span of a maximum of two weeks. Within this time period, the participants refer either to the near past, the present or forthcoming occasions, actions and contacts. Thus, the discussions involve quite a lot of timerelated words and expressions (Juhila, Günther, \& Raitakari, 2014, p. 13). Within this framework, we coded two main functions of Home Screen discussions: (a) checking up on and communicating the client's immediate condition, well-being and home environment; and (b) creating continuity in relation to services, everyday life and workers.

Next we will demonstrate both of these functions by showing and analysing five extracts in more detail. These extracts also illustrate the different ways clients and workers orient to Home Screen to be relevant to their institutional roles and tasks. In all the selected extracts, Home Screen becomes a topic or is referred to in different ways (either directly or indirectly).

\section{Checking up on the Client}

When Home Screen functions as a device for checking and communicating the client's immediate condition, well-being, and home environment the discussions involve topics regarding events in the client's near past and the present. They also involve suggestions and 
references to face-to-face contacts and forms of support outside floating support, such as clients' families, acquaintances, and medical services. Workers make assessments of clients' situations and make sure everything is "okay": have the clients taken their medication, gone to the grocery store, eaten warm meals, cleaned the house, bought the necessary summer clothing etc. Clients, on the other hand, give accounts regarding their current situation. All these checks entail workers' institutional task of making assessments of whether the client's situation requires physical contact or other forms of additional support. Clients' responses on the other hand entail their role as receivers of help and support from the workers and the institution in question.

Extract 1 illustrates how Home Screen functions as a medium to discuss the client's current mental state.

\section{${ }^{2}$ Extract 1.}

1 W: Well yeah, you've got .. (2) a day at the workshop behind you now.

3 C: yeah.

4 (2)

5 W: Yeah, how was your, weekend then?

$6 \quad(5)$

7 C: there was a little bit of being poorly, anxiety and, (--) ((0:00:55)). ((Worker adjusts

8 the volume)) that's why I wasn't really up to participate in that (homecare)

9 presentation.

10 W: right well it was on Friday, that's right.

$11(2)$

12 C: yeah. 
13 W: Did you give us a ring ((probably via Home Screen)) in the weeke-.., at least I

14 didn't hear that you had but, did

15 you have (in mind) that you might have rang us?

$16 \mathrm{C}:(--)((0: 01: 10))$

$17(2)$

18 no, well I just calmed down then, £bit by bit.£

19 W: yeah.

$20(2)$

21 well what..

22 C: $(--)$.

$23(1)$

$24 \mathrm{~W}$ : yep.

$25(2)$

26 how did you feel like, did you have any, means, what helped you then or how?

$27(2)$

$28 \mathrm{C}$ : I just tried to rest and then, (--) ((0:01:36)).

$29(2)$

30 there was some dizziness and, you know, my stomach started to twist and, those kinds

31 of things but then it passed

$32 \mathrm{~W}$ : yeah.

$33(1)$

34 well I wonder that you've not had much, or for a quite a long time you've been quite 35 well like you've not had any anxious days or anything.

$36(2)$

$37 \mathrm{C}$ : there has been, like a really long phase (like there has been) $((0: 02: 05))$ a kind of 
38 smooth feeling.

$39(2)$

$40 \mathrm{~W}$ : yep.

$41 \mathrm{C}:(--)$.

At the beginning of the dialogue the worker is trying to find out the client's immediate condition by referring to and asking about his previous happenings. The client's response to the worker's quite mundane question about the weekend illustrates that this conversation occurs in a certain institutional context. The worker's questions entail that he orients to Home Screen as a device to check the client's current condition and whether the client can manage on his own. These reflect the more general institutional goals of the floating support service to get the clients to recognise the signs of risks and situations that cause them stress (brochure of Floating Support Service). This dialogue illustrates that Home Screen has an important function in the client's recovery process as the checking of the client's situation is used as a means to prevent risks. By asking questions the worker can evaluate whether the client needs other kinds of support services or the physical attendance of the worker.

Extract 2 illustrates how Home Screen affords visual observation of the client's immediate situation.

\section{Extract 2 .}

1 W: Okay, good good. yes. You seem to have done some cleaning there at home as the

2 pile of magazines has disappeared from the floor. ((There are no piles of magazines

3 visible in the background of the client screen))

4 C: yes I have cleaned.

5 W: £well yes. What else did you do other than take out the magazines?£

$6 \quad(2)$ 
7 C: made coffee and, then, did the laundry.

8 W: £uhhuh. That was cleaning?£

9 C: and I did clean up (here) and (--)

$10 \mathrm{~W}$ : yes. Okay. Did the renovation people clean up the mess they left?

$11 \mathrm{C}$ : yes they cleaned up well.

$12 \mathrm{~W}$ : Okay, good, as I noticed then on Wednesday that there was some dust on the floor.

$13 \mathrm{C}$ : yeah.

$14 \mathrm{~W}$ : good that they cleaned up after.

$15 \mathrm{C}$ : yeah.

$16 \mathrm{~W}$ : Yes. (2) ((is looking at the calendar or something on the desk)) Yes, yes, it is,

17 noticeable that you are calmer now than you were during the week.

$18 \mathrm{C}$ : yes I have calmed down since then.. (3)

In this extract the worker orients to Home Screen as a device that offers the possibility to observe the client's living environment and their current mental state. The worker's indirect question about cleaning the house and taking out the magazines would normally be inappropriate in mundane conversations. But in this particular context it is treated as normal since the client responds to it without hesitation. The worker's question also indicates that she has seen the client's house before. The worker also asks some additional questions about the cleaning, which indicates that Home Screen offers rather limited information about the client's living environment and the outcomes of the cleaning. It becomes obvious that Home Screen functions as one part of the worker-client relationship, as there are references to the people and earlier appointments they both recognise. The worker's observation about the client's mental condition clearly indicates that they have a history of working together. These kinds of observations would be impossible during traditional phone calls. What surprised us is that these kinds of visual affordances (Gibson, 1977) of Home Screen are rarely verbalised in the data. 


\section{Creating Continuity}

Besides the function of checking up on the client, we found out that in Home Screen mediated discussions workers and clients prepare for the clients' forthcoming events and tasks. Thus, the participants create continuity both for the services and the client-worker relationship. The workers put together and repeat the events and tasks to come. In addition to this, they also create continuity in relation to the client's everyday life. They take a load off clients' minds, for example, when clients are going to the dentist or to the eye specialist and stress these situations beforehand. The workers also put things into perspective: "It is quite normal to wake up at night" and "It is true that one worries about things, it is only natural". They also give feedback and encouragement to their clients: "you've done great", "you've taken responsibility", "you've been active" etc. Clients also participate in this talk by reflecting on and assessing their own situations a great deal.

Extract 3 illustrates how Home Screen functions in relation to other forms of support.

\section{Extract 3.}

1 (8) W: yes. How should I now, I was just wondering like when, we've been now quite

2 a bit,((looks at something on the desk, a calendar / a notebook etc.)) seen each other

3 through the screen, and it's been like once a week. What do you think, do you have

4 for us any, issues, what our meetings could now.. (3) be in the future? Is this good that

5 we see each other on the screen and you contact us if needed, are there any issues at

6 home that, you'd need..?

$7 \quad(2)$

8 C: well..

9 (1)

$10 \mathrm{~W}$ : ..some help with? At least for a long time there has been nothing really, with

11 household chores there has not been any particular issues after that, beginning but, 
12 what do you think?

13 C: yes (--) ((0:08:57)) I manage them fine and, (2) like that (2) a bit like when, it has 14 changed a bit (--) this screen has been quite good I think (2) support network for me.

15 (like when it now), (-).

$16(2)$

$17 \mathrm{~W}$ : yes.

$18 \mathrm{C}$ : (this is), (--) (come there as well), (-) £(at the office)£, (--) (--).

$19 \mathrm{~W}$ : yes it is. Like, if we think of next week, really the only possible is that if you want 20 sometimes like if you have something, a trip to the city or something like that that you 21 want us to see there or so well yeah, it will do as well. Actually what do you, what do

22 you think that how this would be most useful to you so, that's the way we go.

24 C: yeah.

$25(3)$

26 well, somebody could come here next week to see that if the flat is still £standing up£

27 ((gives a laugh)).

28 W: yeah, yeah. Right.

$29(2)$

$30 \mathrm{C}$ : or should we agree then, on a home visit for next week?

$31(2)$

The extract begins with the worker's inquiry about the client's needs and wishes in regard to the services "they" are providing for him. The worker's orientation is strongly negotiable (Drew \& Heritage, 1992, pp. 23-24; Juhila et al., 2014, p. 21) as he gives the client an opportunity to assess the continuity of his services and his "relationship" to "them". The worker uses the institutional "us" to refer to the organisation that he is representing (see Drew 
\& Heritage, 1992). The client is satisfied with the help Home Screen offers, as it has been an important safety net for him. Nevertheless, he suggests that he could come to the office. The worker does not notice or hear this, as he continues with the negotiable orientation by offering an alternative way of contact and letting the client assess his own service needs. The client does not accept the offer, as he suggests a home visit and also a date for it. What eventually happened was that they agreed a Home Screen discussion for the next week, because the worker did not have time to do the home visit within this timetable. This is an illustrative example of how the Home Screen functions in relation to other facial contacts and how it is oriented as one component of the client's floating support service network.

Extract 4 illustrates how me Screen functions as a medium to sum up and plan the client's goals.

\section{Extract 4.}

1 W: but I will call you in any case at quarter past two tomorrow so..

2 C: yeah

3 W: ..we can then ((coughs))..

4 C: $(--)((0: 27: 46))$.

5 W: .. do that final you know, checking before the weekend. So how do you, ((flips

6 through the calendar) I will go back a bit to those, (2) goals that..

7 C: yeah?

8 W: ..(4) ((writes)) with each of them we stated that, I think you have done really well

9 with those goals, committed to them.

$10(2)$

$11 \mathrm{C}$ : What it requires I think it requires that $[(-)]$ one needs to commit to them. It is

12 between the ears then (--).

13 W: yeah. 
14 yeah. yes.

15 ((makes a marking)) and I think we now have here a good four weeks follow-up time

16 now with that Tiina (a psychiatrist). We'll continue with the same goals and evaluate

17 them and, ((makes a marking)) then with those money issues we could for example in

18 next week's home visit think about a bit. ((writes))

$19(2)$

$20 \mathrm{C}$ : well I think that is okay then.

$21 \mathrm{~W}:(($ writes $)) \mathrm{mm}$.

$22 \mathrm{C}$ : it is a good thing to do.

In this extract, the worker confirms the client's continuity for services and for the helping relationship with the worker herself by summarising the client's forthcoming events. She also summarises the things they have been talking about during Home Screen call. She gives feedback and encouragement to the client, e.g.: "I think you have done really well with those goals". This extract finely demonstrates how Home Screen functions as one component in the client's service continuum as there are many references to other forthcoming contacts (phone call, meeting the psychiatrist, and next week's home visit). The worker strongly orients to her institutional role as she refers to the "goals" that they have been talking about and which will be evaluated with the psychiatrist as well. The client confirms the worker's talk. The client also reflects on and evaluates her situation and what it requires from her in order to achieve the goals (from line 11). Thus, the lexical choice (Drew \& Heritage, 1992) of the client is interesting: "what it requires I think it requires that $[(-)]$ one needs to commit to them. It is between the ears then (--)." This reflects that the institutional goal of getting the client to cope on her own is being actualised. 
Finally, extract 5 demonstrates how the functions of Home Screen are negotiated in the course of the interaction.

\section{Extract 5 .}

1 W: ((is making notes while speaking)) okay. What do you think, when you get

2 anxious, are there any other good means for it than an extra medicine? What do you

3 think, how can you in that kind of situation make use of other means? Or is it so that

4 all means have already been used?

5 C: so what I'd kind of need then is that someone is with me.

6 W: yes, right.

7 C: yeah..

8 W: what about this Screen? Could it serve you at that point?

9 C: well, it depends on who is on the other side.

$10 \mathrm{~W}$ : mm. (2) what do you think, would it make it easier if... (2) we agreed a few

11 screen discussions with other workers as well? What do you think would it be

12 possible to get to know others a bit as well?

$13 \mathrm{C}:(--)$ I can't be myself sort of (--). I get (that) okay, yeah, I'll tell this matter to get 14 quickly away (-) from (the) situation.

$15 \mathrm{~W}$ : yes.

$16(1)$

17 C: yes.

$18(1)$

$19 \mathrm{~W}$ : as, of course, then, when we go towards the summer and, then of course there are

20 some summer vacations and I'm away, for a few weeks and so on, so that anyway,

21 it'd be terribly nice that, certainly we've worked so closely together but that anyway 22 you'd take a chance on trusting others a bit too. 
$23 \mathrm{C}: \mathrm{mm}$

24 (2) sure. it's like as I said that it depends on a bit about who's there on the other side.

$25 \mathrm{~W}: \mathrm{mm}, \mathrm{mm}$

$26 \mathrm{C}$ : that I feel like that someone listens to me for real and kind of that you, you always

27 give

$28 \mathrm{~W}: \mathrm{mm}$

29 (-) (snappy?) answers, so ((laughing)) if there’s £someone similar to you so

$30 £(($ laughing $))$, £then it'd go quite well£

$31 \mathrm{~W}$ : £yeah£ I believe that if you'd only get to know, get more courage so, certainly,

32 everyone will listen to you and talk with you. I don't doubt that for a second.

Before the extract, the worker and the client have been talking about the client's need for "an extra medicine" in case she gets anxious. Then the worker asks the client what she thinks about other ways, other than medication, she could benefit from in those situations. This extract illustrates how Home Screen does not solely function as a device or a medium for discussion in the client's service continuum. Particularly the client's talk represents the importance of knowing and trusting the people she has contact with via Home Screen. The worker does not accept the client's view, as she tries to get the client to trust other workers as well. Maybe she tries to prevent a strong interdependence with the client. This also reflects the more general goal of the floating support services; that of trying to improve the mundane living skills of clients by mapping out their social skills and helping to rehearse them (brochure of Floating Support Service). She is also directing the topic of conversation on behalf of her institutional role (see Heritage, 1997, p. 176; Drew \& Heritage, 1992, p. 49). The discussion also reflects the general goals of monitoring the clients' medicine taking and making clients aware of the meanings of their medication (brochure of Floating Support Service). Nevertheless, the client does not accept the worker's suggestion of making contact with and 
trusting the other workers as well. The client emphasises and prefers the trustworthy relationship in regards to Home Screen only as a technical means of getting contact. This extract illustrates how the functions and meanings of Home Screen are not stable but rather produced and negotiated in the interaction. Extracts 4 and 5 are from the same encounter. They both demonstrate that Home Screen has a place in the client's recovery process as it functions as a medium to talk about the important issues such as the use of medication, client's goals, and money issues.

\section{Discussion}

In this article we have demonstrated that Home Screen has two interconnected functions: checking on and communicating the client's immediate condition, well-being, and home environment and creating continuity in relation to services, everyday life, and workers. Within these two functions Home Screen acts as the following: (a) a medium to discuss the client's current mental state; (b) a medium for visual observation of the client's immediate situation; (c) a medium in relation to other forms of support; and (d) a medium to sum up and plan the client's goals. The functions of Home Screen are not stable but rather produced and negotiated in the course of the interaction between workers and clients.

Although support is increasingly provided in clients' homes, it has been observed that the roles of the professional and the client predominate the home visits. In that sense the floating support has meant "partial institutionalisation of homes" (Juhila et al., forthcoming). We have examined how this institutional "shade" is present and pervasive in Home Screen discussions as well. Home Screen mediated discussions involve and reflect the overall institutional goals of floating support services and particularly those goals that aim to help and advise clients on cleaning, financial matters, medicine taking, creating and maintaining social 
relations, and clients' everyday problems (brochure of Floating Support Service - goals regarding the home visits).

In the selected extracts the workers and clients orient to Home Screen discussion with their institutionally relevant roles. Home Screen enables workers to make observations, suggestions, and initiatives based on visual observations on the condition of the flat or the client's mental state that a normal phone call would exclude. It also enables the client to see the face of the familiar worker that alone can have a calming effect and increase the client's trust towards the worker. On the other hand, it has been observed that the traditional telephone counselling affords more privacy as the client's and professional's gestures and facial expressions are hidden (Rosenfeld, 2002, p. 175). The workers usually choose the topic of conversation, and they are allowed to ask and require details about clients' fairly private issues (see Juhila et al., 2014, p. 20). Clients on the other hand give accounts about their current situation e.g. household chores or mental (and physical) condition mainly without hesitation. Nevertheless, there are no strong asymmetries between the participants, which are more likely to occur in other social and health care contexts, for example in child protection or medical consultations (Juhila et al., 2014, p. 21; Drew \& Heritage, 1992).

Our results indicate that clients are mostly in alignment with workers when it comes to the use of Home Screen and the contents of discussions. This echoes with Perle and Nierenberg (2013, p. 25) who note that clients establish rapport with their teleprovider and are able to provide information as they would in person. As with face-to-face encounters, the office layout, angle of chairs, and ability to minimise interruptions may be of significant importance to the success of telecare (Perle \& Nierenberg, 2013, p. 30; see also Räsänen, 2014). The help provided via Home Screen may have the same possible shortcomings as Mielonen et al. (2002, p. 190) describe regarding the treatment via telepsychiatric services, such as a lack of physical contact (shaking hands and touching) and the sense of smell. On the other hand, the home- 
based telecare devices may enhance the clients' privacy contrary to institutional care with fellow patients and changing carers (Sorell \& Draper, 2012, p. 38). Earlier research on different telecare services also indicates that they may increase the isolation of users if they reduce the number of in-person interactions (Sorell \& Draper, 2012; Huang \& Goldhaber, 2012). By seeing the clients in their home environment and asking questions workers can evaluate the clients' current state and needs for other kinds of support services and/or the need for the physical attendance of the worker. At the same time, the workers can evaluate their own usage of time. Thus, Home Screen crosses over a certain border of the client's privacy as it functions between office-based face-to-face encounters, home visits, and phone calls. On the other hand, when the worker is office-based and client home-based, they are both "on their safe ground". Thus, we claim that Home Screen under study can be understood as a transitional device that sets itself between the home visits, office-based meetings, and traditional phone conversations. In the more sparsely populated areas with geographic distances such as Northern Finland or remote areas of Australia and United States, the importance of Home Screen type of devices are even more promising in enhancing clients' access to services and contacts with professionals (see Schopp et al., 2006; Kennedy \& Yellowlees, 2000).

In mental health floating support services, time is strongly present and negotiated; the past, the present, and the future are continuously talked into being (Juhila et al., 2014, p. 10), which certainly applies also to Home Screen discussions. We discovered that even though the discussions can be fitted into a short time span of a maximum of two weeks, the clients' problems are nevertheless long-term issues. This is illustrated in the discussions, as the workers and clients both know the people and the services they are talking about. The participants also seem to share the frame of psychiatric jargon, for example about the client's symptoms. Thus, Home Screen seems to be suited for that phase of support in which the client and the worker are familiar with each other. The discussions differ e.g. from emergency 
situations where clients and their situations are unknown to workers. In these situations workers may need to check and get acquainted with the clients' previous information from earlier documents or IT-based files (Räsänen, 2014; Burton \& van den Broek, 2009).

\section{Conclusion}

Our small-scale data does not allow us to generalise the results and apply them to other settings of human service work. However, checking the client's condition, well-being, and some parts of the home environment as well as creating continuity for the client's services, every life, and for the relationship with workers are fairly recognised goals in other mental health settings too. Home Screen functions as one part of the "bigger picture" of the client's recovery process, service continuum, and milieu. Home Screen does not totally replace home visiting, nor does it function separately from other forms of support. When Home Screen is applied to replace e.g. one or two home visits, it can assist workers to plan their use of time. Within this device, workers are portrayed as supporters and activators who aim to secure clients' service continuity by constructing a "survival frame" for them. This frame is, however, always tightly connected to clients' other services and contacts. Thus, Home Screen is a device that enables to carry out worker-client interaction with certain limitations and within certain frames.

This paper has demonstrated the role of telecare in a specific field of human services: that of marginalised and means-tested mental health floating support. An important question is how telecare services, such as Home Screen, would function and if it would be appropriate in contexts that comprise a great deal of institutional control and assessment; for example in child protection. Alternatively, the suitability of telecare when working with young people deserves 
discussion (Slone, Reese \& McClellan, 2012). For them, Home Screen is likely to present a familiar mode of communication.

Overall, our findings support the general purpose of telecare services that aim to enable clients to remain in their own homes despite their care needs (Eccles, 2010; Sorell \& Draper, 2012). Our research also supports the idea that mental health floating support work can be translated into a telecare format, at least to a certain extent (see Perle \& Nierenberg, 2013). As an emergency device it can add value to more traditional home visits. However, our data included only beforehand agreed discussions. Research on telecare as institutional interaction taking place in actual practice situations produces a specific perspective on the ways human service workers need to balance practice with the frames of different technologies (Räsänen, 2014; Saario, 2012; Saario, Hall \& Peckover, 2012). Thus, studying telecare as institutional interaction is vital to inform the future implementation of similar ICTs in human services, especially in regard to their potential in emergency situations in which it is important for clients to reach the workers when in need, no matter the distance between them.

\footnotetext{
1 The study draws on a larger research project which examines everyday practices in five supported housing and floating support services in Finland and England (Responsibilization of Service Users and Professionals in Mental Health Practices, 2011-2016). The data of this study is exclusively from the one setting in which telecare has been implemented. However, we utilise the background information provided by the larger data corpus to reach contextual understanding on floating support services

$\begin{array}{lr}{ }^{2} \text { Transcription symbols: } \\ W & \text { Worker } \\ C & \text { Client }\end{array}$

(2) Pause longer than 1 second with number indicating the length in seconds

[ Overlapping starts

Overlapping ends

? Rising intonation

word Emphasising a word or a sequence

£word $\quad$ A word or a sequence said with a smile or a laughter

(-) Omitted word or a part of a word

(--) $\quad$ Omitted sequence

(word) Unclear word or a sequence

wor- Unfinished word (hyphen)

(()) Transcriber's comments
}

(Identification data has been either removed or changed from the data by using pseudonyms). 
Acknowledgment: This article is part of the research project Responsibilization of Service Users and Professionals in Mental Health Practices, funded by the Academy of Finland. We would like to thank the other members of project and DANASWAC (Discourse and Narrative Approaches to Social Work and Counselling) network for their valuable comments.

\section{References}

Aceros, J.C., Cavalcante, M-T.L., Domenech, M. (2013). Telecare user's place identity: A conversation analysis. Revista Latinoamericana de Psicologia, 45(1), 81-95. [In Spanish, with an English abstract]

Barlow, J., Bayer, S., \& Curry, R. (2005). Flexible homes, flexible care, inflexible organisations? The role of telecare in supporting independence. Housing Studies, 20(3), 441-456.

Beale, S., Truman P., Sanderson, D., \& Kruger J. (2010). The initial valuation of the Scottish telecare development program. Journal of Technology in Human Services, 28(1-2), 60-73.

Brochure of Floating Support Service. (The name of the service is anonymized)

Burton, J., \& van den Broek, D. (2009). Accountable and countable: Information management systems and the bureaucratization of social work. British Journal of Social Work, 39(7), 1326-1342.

Button, G. (1993). The curious case of the vanishing technology. In G. Button (ed.) Technology in working order: Studies of work, interaction, and technology (pp. 10-28). London \& New York: Routledge.

Crutchfield, J., \& Burnie, A. (2001). Fitting the bill: Developing a floating support service. Housing, Care and Support, 4(1), 27-30.

Developing mental health service users' housing (2012). Reports of Ministry of the Environment 10. Helsinki: Ministry of the Environment.

Drew, P., \& Heritage, J. (1992). Analyzing talk at work: An introduction. In P. Drew \& J. Heritage (eds.) Talk at work: Interaction in institutional settings (pp. 3-65). Cambridge: Cambridge University Press. 
Drew, P., \& Sorjonen, M-L. (1997). Institutional dialogue. In T.A. Van Dijk (ed.) Discourse Studies: A Multidisciplinary Introduction (pp. 92-118). London: Sage.

Eccles, A. (2010). Ethical considerations around the implementation of telecare technologies. Journal of Technology in Human Services, 28(1-2), 44-59.

Eräsaari, L. (1999). Social work 'through the lens'. In S. Karvinen, T. Pösö \& M. Satka (eds.) Reconstructing social work research (pp. 111-136). Jyväskylä: SopHi.

Frennert, S. A., Forsberg, A., \& Östlund, B. (2013). Elderly people's perceptions of a telehealthcare system: Relative advantage, compatibility, complexity and observability. Journal of Technology in Human Services, 31(3), 218-237.

Frers, L. (2009). Space, materiality and the contingency of action: A sequential analysis of the patient's file in doctor-patient interactions. Discourse Studies, 11(3), 285-303.

Garfinkel, H. (1967). Studies in ethonomethodology. Cambridge: Polity Press.

Gibson, J.J. (1977). The theory of affordances. In R. Shaw \& J. Bransford (eds.) Perceiving, acting, and knowing: Toward an ecological psychology (pp. 67-82). Hillsdale, NJ: Lawrence Erlbaum.

Heath, C., \& Hindmarsh, J. (2002). Analysing interaction: Video, ethnography and situated contact. In T. May (ed.) Qualitative research in action (pp. 99-121). London: Sage.

Heath, C., \& Luff, P. (2000). Technology in action. Cambridge: Cambridge University Press.

Hebert, M. (2001). Telehealth success: evaluation framework development. In V.L. Patel, R. Rogers \& R. Haux MEDINFO 2001. Studies in Health Technology and Informatics, (pp. 1145-1149). Amsterdam: IOS Press.

Heritage, J. (1997). Conversation analysis and institutional talk. In D. Silverman (ed.) Qualitative analysis: Issues of theory and method (pp. 161-181). London: Sage.

Juhila, K., \& Abrams, L. (2011). Special issue editorial: Constructing identities in social work settings. Qualitative Social Work, 10(3), 277-292. 
Juhila, K., Günther, K., \& Raitakari, S. (2014). Negotiating mental health rehabilitation plans: joint future talk and clashing time talk in professional client interaction. Time \& Society. Published Online 27 February 2014. Doi: 10.1177/0961463X14523925.

Juhila, K., Mäkitalo, Å., \& Noordegraaf, M. (2014). Social work discourse in practice. In C. Hall., K. Juhila, M. Matarese, \& C. van Nijnatten (eds.) Analysing social work communication (pp. 9-24). Abingdon: Routledge.

Juhila, K., Hall, C., \& Raitakari, S. (forthcoming). Interaction during mental health floating support home visits: Managing host-guest and professional-client identities in home spaces. Social and Cultural Geography.

Kennedy, C., \& Yellowlees, P. (2000). A community-based approach to evaluation of health outcomes and costs for telepsychiatry in a rural population: Preliminary results. Journal of Telemedicine and Telecare 6(1), 155-157.

Kubota, M., Hosoda, K., Eguchi, K., Furuya, A., Nishijima, Y., Nakao, K., \& Kinoshita, A. (2013). Videophone-based multimodal home telecare support system for patients with diabetes. Diabetology International, 4(1), 52-29.

Mielonen, M-L., Ohinmaa, A., Moring, J., \& Isohanni, M. (2002). Videoconferencing in telepsychiatry. Journal of Technology in Human Services 20(1-2), 183-199.

Perle, J., \& Nierenberg, B. (2013). How psychological telehealth can alleviate society's mental health burden: A literature review. Journal of Technology in Human Services, 31(1), 22-41.

Pilnick, A., Hindmarsh, J., \& Teas Gill, V. (2009). Beyond 'doctor and patient': Developments in the study of healthcare interactions. Sociology of Health \& Illness, 31(6), 787-802.

Plan for mental health and substance abuse work (2010). Reports of the Ministry of Social Affairs and Health 5/2010, Helsinki.

Report on the development of mental health service users' housing (2012), Reports of the Ministry of the Environment 10/2012. Retrieved January, 15, 2014 from http://www.ym.fi/download/noname/\%7B317728A3-41A3-4DA8-8769-

CCE0204B029F\%7D/40238 (Originally in Finnish) 
Responsibilization of Service Users and Professionals in Mental Health Practices (2011-2016). Research Project. Academy of Finland.

Rosenfeld, M. (2002). Electronic technology for social work education and practice: The application of telephone technology to counselling. Journal of Technology in Human Services, 20(1-2), 173181.

Räsänen, J-M. (2014). Emergency Social Workers Navigating between Computer and Client. British Journal of Social Work. Doi: 10.1093/bjsw/bcu031. First Published Online April 16, 2014.

Saario, S. (2012). Managerial Reforms and Specialised Psychiatric Care: A study of resistive practices performed by mental health practitioners. Sociology of Health and Illness, 34(6), 896-910.

Saario S., Hall, C., \& Peckover, S. (2012). Inter-professional electronic documents and child health: A study of persisting non-electronic communication in the use of electronic documents. Social Science \& Medicine, 75(12), 2207-2214.

Schopp, L., Demiris, G., \& Glueckauf, L. (2006). Rural backwaters or front-runners? Rural telehealth in the vanguard of psychology practice. Professional Psychology-Research \& Practice, 37(2), 165173.

Scottish Government (2008). Seizing the opportunity: Telecare strategy 2008-2010. Edinburgh: Crown copyright.

Sharples, A., Gibson, S., \& Galvin, K. (2001). 'Floating support': Implications for interprofessional working. Interprofessional Journal of Care, 16(4), 311-322.

Slone, N. C., Reese, R., \& McClellan, M. J. (2012). Telepsychology outcome research with children and adolescents: A Review of the literature. Psychological Services, 9(3), 272-292.

Sorell, T., \& Draper, H. (2012). Telecare, surveillance and the welfare state. The American Journal of Bioethics, 12(9), 36-44.

T-Seniority. Expanding the benefits of information society to older people through digital TV channels (2008-2010). Retrieved January, 15, 2014 from http://tseniority.idieikon.com/ 
Wakefield, B.J., Holman, J.E., Ray, A., Morse, J., \& Kienzle, M.G. (2004). Nurse and patient communication via low-and high-bandwidth home telecare systems. Journal of Telemedicine and Telecare, 10(3), 156-159.

Wilińska, M., \& Bülow, P. (2014). Video recording as a research and practice intervention. Paper presented in DANASWAC (Discourse and Narrative Approaches to Social Work and Counselling) seminar, Durham, England, 20.8.2014.

Wootton R., Geissbuhler, A., Jethwani, K., Kovarik, C., Person, D., Vladzymyrskyy, A., Zanaboni, P., \& Zolfo, M. (2012). Long-running telemedicine networks delivering humanitarian services: Experience, performance and scientific output. Bulletin of the World Health Organization, 90(5), 341-347.

Zimmermann, D.H. (1998). Identity, context and interaction. In C. Antaki \& S. Widdicombe (eds.) Identities in talk (pp. 87-106). Sage: London.

Zissman, K., Lejbkowicz, I., \& Miller, A. (2012). Telemedicine for multiple sclerosis patients: Assessment using Health Value Compass. Multiple Sclerosis, 18(4), 472-480. 